\title{
OLIVEIRA, Jelson. NegaÇão e Poder: do desafio do NiIlismo aO Perigo da tecnologia, Caxias do Sul, EDUCS, 2018, 496 P. ${ }^{1}$
}

\author{
Antonio Valverde ${ }^{2}$ \\ "Um verme rói - enorme roer - \\ Um verme rói minuciosamente \\ Desde que o tempo sentou-se sobre si [...] \\ Um verme roerá a morte." \\ (MENDES, 1995) \\ "Pertencemos a uma época cuja civilização corre o perigo \\ de ser destruída pelos meios da civilizaçáo." \\ (NIETZSCHE, 2000) \\ “O que pode servir como bússola? A previsão do perigo."
}

(JONAS, 2006)

OLIVEIRA, J. Negaçáo e Poder: do desafio do niilismo ao perigo da tecnologia, Caxias do Sul, EDUCS, 2018, 496 p

Instabilizador. O livro em pauta resulta de pesquisa prospectiva, sem dispensar a acumulada de anterioridades acadêmicas do Autor. Assim, mobiliza-se por interrogaçóes latentes, ora explicitadas, ao panorama éticofilosófico contemporâneo, sob o espectro da niilidade, antes, do niilismo. Conduzidas ao fio da navalha do movimento de um entreconhecer dialético

${ }^{1}$ Jelson Roberto de Oliveira é Doutor em Filosofia pela UFsCar, Professor do Programa de PósGraduação em Filosofia da PUCPR, Coordenador do GT de Filosofia da Tecnologia e da Técnica da ANPOF, autor de vários estudos acerca da filosofia de Hans Jonas, Coordenador do Centro Hans Jonas Brasil e da Cátedra Hans Jonas da PUCPR.

2 Professor do PEPG em Filosofia da PUC-SP, São Paulo, SP - Brasil. https://orcid.org/00000002-1713-7914 E-mail: valverde@pucsp.br

https://doi.org/10.1590/0101-3173.2021.v44dossier.16.p275

This is an open-access article distributed under the terms of the Creative Commons Attribution License. 
movido ao atrelar o hóspede indesejado e seu par natural, o hospedeiro. Postados desde a provável improficiência de um e a dilacerada misologia de outro: o ressentir-se da ferrugem do tempo. Todavia, tal tarefa sisifiana não pode não se revelar demarcada, de modo mais geral, do infamiliar, inavegado, indevassado, recôndito, trevoso. Porém, sob processo de travessia - travessia do niilismo -, em vista do horizonte de sua negação. Ou não, se se considerar o niilismo - se o niilismo for compreendido como pressuposto -, qual um drama psicótico filosófico, em movimento subterrâneo, desde a Antiguidade. Apresentado, por certo, tal o mais robusto substrato da Filosofia, derivado em parte do zoroastrismo e de pares análogos complementares. Quiçá, especulativamente, pode-se emparelhá-lo ao Eclesiastes, por espelhar a solidão, a vaidade, o homem idêntico ao animal, no mesmo passo em que lança à imaginaçáo o contraponto da alegria de viver frente o mal-estar, que, por hipótese, se instaurava nos desvãos da existência humana, desde a Antiguidade. Contudo, o termo adentrara a cena filosófica moderna, desde que Hamilton (17551804) nomeou de niilismo a negação da realidade substancial, identificando Hume como niilista, por negar a realidade substancial ( $s i c)$. Na filosofia alemã, ao final do século XVIII, Jacobi e Fichte polemizaram acerca do niilismo como contestação do racionalismo idealista.

Todavia, a doença incurável, ora desvelada, no detalhe, aos limites da história da filosofia e da sabedoria religiosa, parece remexer, desacomodando os traumas residuais de suas formaçóes e o desenlace de ambas. Traumas constatados com precisão pelos sintomas inaugurais, na forma gnosis da Antiguidade tardia, detectada por Hans Jonas. Prosseguido pelo lastro pessimista, em curso exaltado na Modernidade - talvez estendido da antecipada filosofia de Giacomo Leopardi -, um dos que melhor captara o fim do ethos antigo. Apesar de Nietzsche referir-se pouco ao Italiano, em suas obras. Assim, se se tomar o niilismo como drama psicótico, dada a sua compreensão profunda e o grau de verdade que contém, a operar o interdito, o mais provável interdito da filosofia e do homem, tem-se um problema ético grave, verdadeiro. Na contramão da formulação precária, abreviada da falta de sentido da vida e do fastio da humanidade com a própria humanidade. Afinal, o psicótico guarda uma verdade fundante, porém, sem poder revelá-la, porque ninguém a compreenderia, se fosse explicitada. Nem a aceitaria, dado o grau de perplexidade que contém. Talvez, a ponto de uma defectibilidade, que somente ao resguardo no trato do niilismo figure mimetizado, através da técnica sedutora de mais insinuar que desnudar sua verdadeira face, a oculta. 
Se os filósofos do tempo presente se mostram esquecidos da arma da crítica, espontânea, generosa, pontiaguda, que se encontra recolhida, afrontada por remordimentos, na forma generalizada de parálise do pensamento radicalmente crítico, findando por não gerarem, grosso modo, contribuições filosóficas à altura da crise contemporânea - a crise da razão a-histórica e seus entornos. Salvo poucas exceções. Assim, o desvelar pela sondagem filosófica do sentimento do tempo e do agir moral sob o vácuo ético, ao encarar o niilismo refletido da tecnologia, pode ser um promissor roteiro para o desarme da catástrofe civilizacional em curso, sob todas as ordens e de muitos modos. À sombra globalizada da barbárie emergida, o presente encontra-se prevalente de um tipo de enfrentamento filosófico, como se lê nos capítulos de Negação e poder - título que corresponde plenamente ao conteúdo.

O sentimento do tempo presente dá a ver o avesso do avesso do avesso da civilização, que é civilidade, florescida dentre os povos antigos, ao vencerem a barbárie originária, registrada por Giambattista Vico, em Ciência Nova. Contudo, o Napolitano alerta que a barbárie é o fantasma da História sempre a rondar, ameaçador, as conquistas civilizacionais (VICO, $2005, \$ 603, \$ 488, \$ 817)$. Para Vico, a Idade Média fora regressiva em relação aos alvores civilizacionais (VICO, 2005, $₫$ 224, $₫ 525, \rrbracket 645$ ). Entretanto, o processo de recepção seletiva e de repaginação civilizacional, operado pelos humanistas renascentistas, novamente projetou e estendeu as alturas civilizatórias adquiridas. Porém, sob o perigo representado pela filosofia cartesiana, dado o excesso de razão, de racionalidade, com que a promover o desmonte das promessas humanistas e por projetar as alturas alcançadas pelo Esclarecimento. Todavia, a civilização moderna descortinou-se trôpega, durante a Primeira Guerra Mundial, que pode ter encarnado a efetivação do niilismo prognosticado por Nietzsche: a roedura, a decadência, a corrosão ética, de par com uma crise aguda do capital a prenunciar outras em ciclos cada vez mais próximos, como os surtos psicóticos de uma pessoa detentora de transtornos mentais. Até o momento de um surto final, ininterrupto, como parece ocorrer com o modo de produção capitalista, hoje.

Assim, a Primeira Guerra Mundial acede o corte, a ruptura com o passado eloquente e malogrado da civilização. Por suposto que os valores fortes - uma vez postos à prova -, não teriam suportado o assalto, sucumbindo à voracidade destrutiva do tempo estilhaçado, qual vidraça da pintura Le Clef des Champs, de René Magritte, 1936, que está no Museo Nacional Thyssen- 
Bornemisza, Madrid. ${ }^{3}$ A História posterior mostrou a derrocada sem fim das alturas civilizacionais ético-políticas alcançadas, de par com o progresso vazio, contrariamente, ao avanço da pesquisa científica sem freios éticos e de sua aplicabilidade técnica, sob regimes políticos autoritários em qualquer parte do hemisfério ou continente, como se fosse um destino manifesto humano, trágico, irreversível. Mesmo que abrangidos, ideologicamente, pela funcionalidade do Estado do Bem-Social, enquanto existiu e nos arremedos colonizados em baixo relevo, como ocorrera no caso nacional entre os governos FHC e Lula todos esgotados ou em esgotamento.

Enfim, de um tempo em que há tantos fins, tantos encerramentos, tantas destruiçóes, aniquilamentos, tantas mortes. Como se o tempo presente fosse já um tempo póstumo e sem futuro próximo, senão de catástrofes sobrepostas. A ponto de nenhum futuro civilizacional alternativo se apresentar, largamente, como tal, de face mais qualificada que o cumprido, pois, o que se constata é o reforçar da aparência de sobrevida de um morto vivo, que cerceia as possibilidades de superaçáo da fatalidade anunciada e cumprida, ou descumprida em fatalidade: a do capital. Para isso, as teorias minguaram, frágeis, passadas, sem utilidade para a necessária compreensão do presente, ao menos sob a chave de análise do beco sem saída representada pelo verme da irracionalidade niilista. Ou não?

Da Primeira Guerra Mundial em diante, a História, mestra dos homens, que guarda os conhecimentos científico e filosófico, as sabedorias religiosa e artística, e, por consequência, o destino da própria humanidade como um todo, vê rolar escada abaixo as aquisiçóes civilizacionais mais significativas, em prolongado outono. Nem o liberalismo, o Estado do Bem-Estar Social, nem a filosofia, a antropologia, a psicanálise, o socialismo, a Declaração dos Direitos Humanos, a sociedade civil a la Hegel, nem a defesa do meio ambiente, as guerras civis, nem mesmo a ciência e a tecnologia conseguem conter a barbárie globalizada, que se impôs. Tudo ocorrendo sob a crise estrutural do capital e de sua lógica irredutível, caracterizadas pela precarização do trabalho, de par com o esgarçamento da classe operária, o inevitável emperramento da luta de classes e a exploração exacerbada e ascendente da expropriação do mais-valor. Contraditoriamente, sob o surpreendente acúmulo de capital.

Jelson Oliveira circunscreve a Segunda Guerra Mundial como a época da irrupção mais aguda do substrato niilista presumido por Nietzsche,

${ }_{3}^{3}$ Disponível em: https://www.museothyssen.org/en/collection/artists/magritte-rene. Acesso em: 30 dez. 2020. 
estendido por Heidegger e incorporado e analisado por Hans Jonas, para além do fenômeno em si, em vista da possibilidade de suplantá-lo, firmado a partir do estudo da gnosis antiga, da filosofia biológica e da ousada tentativa de construção de uma ética de responsabilidade, votada à civilização tecnológica.

Porém, ao tempo da Primeira Guerra Mundial, surgiu a pandemia nomeada de Gripe Espanhola, entre janeiro de 1918 e dezembro de 1920, supostamente emergida de aglomeramentos militares, se em hospital francês ou se em forte militar no Kansas, no Estados Unidos, os registros variam, a peste não. Passados cem anos, a pandemia-endemia Covid-19 trouxe à cena bárbara milhares de mortos e o multiplicado número de infectados, que figuram como alegoria, enquanto metáfora continuada e acabada, da civilizaçáo combalida. Ou será a realidade da crise continuada - de modo nada alegórico -, sem interrupção do capital? Sinal forte do tempo presente, cujas demandas poderão ser conferidas na obra em pauta, particularmente, nos interstícios dela, em seu substrato.

Ao mesmo passo, Walter Benjamin, calcado no materialismo histórico, à guisa de anotação para alguma utilização posterior, sem necessariamente compor parte de sua filosofia das teses acerca da História, registrou: "Nunca houve uma época que não se sentisse 'moderna' no sentido excêntrico, e que não tivesse o sentimento de se encontrar à beira de um abismo. A consciência desesperadamente lúcida de estar em meio a uma crise decisiva é crônica na história da humanidade. Cada época se sente irremediavelmente nova. O 'moderno', porém, é tão variado como os variados aspectos de um mesmo caleidoscópio." (BENJAMIN, 2007, p. 587). ${ }^{4}$

Se a humanidade, historicamente, sempre se imaginou à beira do abismo, contudo, há mais proximidade de tal risco, náo por acaso, afigurado pelas evidências aterradoras do presente. Entanto, ainda haverá alguma esperança ou não mais, na primeira quadra do século XXI, para os rumos civilizacionais? A inserção do termo "perigo" no título da obra e seu significado no desenvolvimento argumentativo aponta para o caos instalado, do qual o esforço de compreensão não sugere por completo algum epílogo, diga-se, favorável. Pressuposto que o niilismo possa ser considerado objeto de uma

${ }^{4}$ No original, BENJAMIN, W. Passagen-Werk. Konvolut S, Malerei, Jugendstil, Neuheit, Fragment S1a, 4, Suhrkamp 1983, Seite 677: "Es hat keine Epoche gegeben, die sich nicht im exzentrischen Sinne ,modern' fühlte und unmittelbar vor einem Abgrund zu stehen glaubte. Das verzweifelt helle Bewusstsein, inmitten einer entscheidenden Krisis zu stehen, ist in der Menschheit chronisch. Jede Zeit erscheint sich ausweglos neuzeitig. Das ,Moderne' aber ist genau in dem Sinne verschieden wie die verschiedenen Aspekte ein und desselben Kaleidoskops." 
travessia humana, até o instante de autossuprimir-se em vista do surgimento de um homem novo, um tipo homem novo, do jargáo filosófico nem niilista nem cristão, desde o devir histórico. Se houver tempo físico - em vista de provável colapso da natureza -, para o advento inaugural de uma época livre das amarras do último surfar sobre a maré vazante do ethos antigo, operado por Nietzsche, restado às calendas. - Às margens de um (novo) outro abismo.

Movido pelo logos interrogante, Jelson Oliveira escreveu Negação e Poder: do desafio do niilismo ao perigo da tecnologia, armado da crítica acumulada desde o horizonte nietzschiano, prosseguido de estudos da filosofia heideggeriana e da jonasiana, dentre outros. Se outros estudiosos de Hans Jonas identificaram o substrato de seu pensamento filosófico pelo tema da vida, o da morte e o da liberdade, Oliveira identifica no niilismo o fundamento e a expectativa de uma superação, em torno do qual perfila as recorrências necessárias para elucidação e construção de uma ética para a civilização tecnológica, tendo a técnica como a mais recente e perigosa encarnação do niilismo. Para Jonas, ambos, niilismo e técnica, devem ser analisados e combatidos com as armas da crítica filosófica, com base no kantismo e na fenomenologia existencialista de matriz heideggeriana. Contudo, para além de tais bases, de sorte a inaugurar um novo padrão de pensar, $\mathrm{O}$ Filósofo parece as ter utilizado como escada de subir. $\mathrm{O}$ que não significa garantia de que o niilismo, ou antes, a niilidade, poderão ser transubstanciados em um platô ético-filosófico, superior. Mas a aposta ética está lançada.

A excelente contribuição filosófica de Negação e Poder encontra-se, dentre outras qualidades exemplares, na habilidade do Autor de pensar a tecnologia como o braço materializado do niilismo, sua mais completa tradução, no presente, sob o arco da imaginaçáo heurística do temor e da pressuposta utopia tecnológica, eixos lapidares do constructo jonasiano. A par do recurso metódico fenomenológico a favorecer o ato de descrever o "fenômeno" da sem finalidade da existência humana, posto pela problematizante interpretaçáo de Nietzsche à decadência ocidental, compósita com a via heideggeriana.

Assim, o niilismo finda por ser uma forma ética antropofágica, a devoração catártica e expandida da civilização. $\mathrm{Ou}$, antes, sob larga concessão, a disposição para um tipo de antropodiceia, que é, grosso modo, o arco de estudos da natureza humana e dos fins morais. Entretanto, sem oportunidade de o homem individual conquistar a si mesmo, dada a crise da subjetividade, diferente de "a famosa história do rei Vishvamitra, que através de milênios de automartírio alcançou tal sentimento de poder e confiança em si, que 
empreendeu a tarefa de construir um novo céu: o símbolo apavorante da mais antiga e mais nova experiência dos filósofos na terra - todo aquele que alguma vez construiu um 'novo céu', encontrou o poder para isso apenas no próprio inferno..." (NIETZSCHE, 1998, III, S 10). Porque, também, “[Q] uem realmente possui a si mesmo, isto é, conquistou definitivamente a si, vê doravante como privilégio próprio castigar-se, perdoar-se, compadecer-se de si mesmo: ele não precisa concedê-lo a ninguém, mas pode livremente passá-lo às mãos de outro, de um amigo, por exemplo - mas sabe que assim confere um direito, e que direitos podem ser conferidos apenas desde que se possua poder" (NIETZSCHE, 2004, \$ 437). - Aqui se abre um debate acerca do resgate da subjetividade e o "homem coletivo", como quer Hans Jonas.

Afinal, o niilismo parece encarnar um tipo ético polífago das aquisiçóes éticas tradicionais, porque não perspectiva o futuro, antes o aniquila, antecipadamente, qual a volúpia da serpente Píton, nascida após o dilúvio. Porém, para ser destruída por um Apolo redivivo. Assim, o niilismo, até certo ponto, expóe uma variante ética de viés inócuo, que, se naturalizado, como tudo que é inócuo, mostra-se venéfico. Eis a sua tragédia. Porque o homem (trans)nietzschiano pode se autoconquistar, independentemente das vicissitudes da vida, da ordem social opressiva, das doenças, da morte. - Acaso, existirá, poderá existir esse protótipo de homem? Aquele da antropologia nietzschiana, com corpo de César e alma de Cristo, incompreendido dos seus leitores contemporâneos.

Assim, o niilismo encarna a irrupção da destruição ética ao limite do colapso ambiental, incrustado à tecnologia. De outra mão, um estudioso prega a aceleração do niilismo, de modo a superá-lo, em vista da possibilidade de uma nova interrelação das espécies. Porém, a perspectiva nietzschiana do niilismo guarda o vazio, o nada, mesmo se considerada como travessia.

O livro é composto de cinco capítulos, antecipados de o "Prefácio: O espírito da época", assinado por Michael Hauskeller, da Universidade de Liverpool, UK, com reconhecimento elogioso à obra, e da "Introdução", em que o Autor contextualiza o cenário histórico-filosófico da obra. Após, no Capítulo 1, "Faces do Niilismo", analisam-se as posiçôes nietzschiana, heideggeriana, e o contraponto jonasiano a partir do niilismo gnóstico. No Capítulo 2, cuida-se das "Formas de niilismo", decompostas em niilismo cósmico, antropológico e ético. No 3, "O niilismo da tecnologia", disseca-o pelos aspectos de "poder incrementado em atividade permanente"; "vontade de ilimitado poder"; "ignorância dos fins e ausência de valor" e "a utopia como 
negação". Passo seguinte, no Capítulo 4, "O transumanismo é um niilismo", direciona-se à abordagem sob três movimentos: "o ser humano em questão"; "a humanidade como doença e o espírito melhorista do progresso" e "a secularização das promessas religiosas". Por fim, no Capítulo 5, circunscrevese o "Enfrentamento do niilismo", como desemboque de toda arquitetura mostrada, anteriormente, passada pelas temáticas "revolução ontológica", "nova antropologia", ética da responsabilidade", em vista do encerramento da discussão com a reflexão acerca do "horizonte do futuro".

Porém, há ainda a oportuna reflexão contida no "Epílogo", intitulado "Sísifo, entre a negação e poder", em que se lê: "É aí, na paisagem da pedra, que a pergunta central de Camus retorna: Por que o homem e não antes $o$ nada? $\mathrm{Ou}$, em termos jonasianos: Por que a humanidade deve ser e não antes arriscar-se, como espécie, em tais apostas? Mesmo aí, Sísifo é o paradigma. [...] (Contudo), o novo Sísifo vive uma situação existencialmente coletiva. Nele, a incerteza do fim e do valor assume repercussões inéditas, que levam a filosofia à sua primeira tarefa cósmica." (OLIVEIRA, 2018, p. 481).

Conduzida ao fio da navalha, a reflexão reitera o perigo da tecnologia. De um mito a outro, frente ao niilismo, também Prometeu desacorrentado fulgura qual promotor desavisado da abissal controvérsia entre otimismo e pessimismo, contemporâneos. Todavia, "Prometeu sacudiu os braços manietados [...] / Pela primeira vez a víscera do herói, / Que a imensa ave do céu perpetuamente rói, / Deixou de renascer às raivas que a consomem. / Uma invisível mão as cadeias dilui; / Frio, inerte, ao abismo um corpo morto rui; / Acabara o suplício e acabara o homem (MACHADO de ASSIS, 2015, p. 548).”

Ao sentimento do tempo: um verme roerá a morte, que é o verdadeiro niilismo?

\section{- À boa leitura!}

Afinal, não é a qualquer hora que surge um livro instabilizador!

\section{REFERÊNCIAS}

BENJAMIN, W. Passagens. Tradução de Irene Aron e Patrícia de Freitas Camargo. Belo Horizonte: UFMG/Imprensa Oficial, 2007. 
JONAS, H. O Princípio Responsabilidade: ensaio de uma ética para a civilização tecnológica. Tradução de Marijane Lisboa e Luiz Barros Montez. Rio de Janeiro: Contraponto/PUCRio, 2006.

MACHADO DE ASSIS, J. M. Obra Completa. v. III, São Paulo: Nova Aguilar, 2015.

MENDES, M. Poesia Completa e Prosa. Organizada por Luciana Stegnano Picchio. Rio de Janeiro: Nova Aguilar, 1995.

NIETZSCHE, F. Genealogia da Moral: uma polêmica. Tradução de Paulo César de Souza. São Paulo, 1998.

NIETZSCHE, F. Humano, Demasiado Humano: um livro para espíritos livres. Tradução de Paulo César de Souza. São Paulo: Companhia das Letras, 2000.

NIETZSCHE, F. Aurora. Tradução de Paulo César de Souza. São Paulo: Companhia das Letras, 2004.

OLIVEIRA, J. Negaçáo e Poder: do desafio do niilismo ao perigo da tecnologia, Caxias do Sul, EDUCS, 2018, 496 p

VICO, G. Ciência Nova. Tradução de Jorge Vaz de Carvalho. Lisboa: Fundação Calouste Gulbenkian, 2005. 
VALVERDE, A. 